\title{
A COMPARATIVE STUDY OF ACCIDENT AND NEAR MISS REPORTING SYSTEMS IN THE GERMAN NUCLEAR INDUSTRY AND THE NORWGIAN OFFSHORE INDUSTRY
}

\author{
Arne Jarl Ringstad \\ Rogaland Research \\ Stavanger, Norway \\ Steffen Szameitat \\ Technical University of Berlin \\ Berlin, Germany
}

\begin{abstract}
A basic assumption in modern safety management is that accidents are preventable through effective feedback control; i. e. through mechanisms by which information about accidents and near misses is utilised as a basis to increase the level of safety. In spite of their popularity, however, previous research has shown that it is frequently difficult to make Accident and Near Miss Analysis Systems (ANMAS) work according to intentions. The present paper presents results from a comparative study of ANMASs in the German nuclear industry and the Norwegian offshore industry. Both industries have a strong emphasis on incident recording and analysis. However, there are important differences between the two industries regarding what events are understood as "incidents", what information on incidents is collected, how the information is processed, and how corrective actions are developed and implemented. These differences are analysed in light of distinctive features of the two industries (e.g. risk scenarios, technology, organisation), legislative factors, and social and cultural variables. It is argued that although different industry sectors may have a lot to learn from each other regarding how to handle accident and near miss reporting, the efficiency of a particular ANMAS must be evaluated relative to the industry's frame conditions.
\end{abstract}

\section{INTRODUCTION}

A basic assumption in safety management is that accidents are preventable through effective feedback control; i. e. through mechanisms by which information about accidents and near misses is utilised as a basis for actions to increase the level of safety (Kjellèn, 1998; Sitkin, 1995; van der Schaaf, Lucas \& Hale, 1991). The prevalent use of accident and near miss databases in high-risk industries, and the recourses spent on registering and analysing information on such events, are two manifestations of the importance attached to historical data in modern safety management. The latter years rapid advances in information technology have further strengthened the role played by accident and near miss data. User friendly software, fast working computers and networks have brought safety managers an increasingly vast amount of easily accessible data, and have made it possible to perform extensive statistical analyses in a matter of minutes. Monthly safety reports, causal analyses and development of risk reducing measures, are some well-known examples of how experience data are utilised in he industry's day-to-day safety work.

In spite of their popularity, the research literature does not give unequivocal support to the usefulness ANMAS in safety management (see Ringstad, 2000 for a review). van der Schaaf (1991) and Kjellén (1998), although the conceptualise the different sub-phases somewhat differently, both describe ideal requirements to an ANMAS according to an input-throughputsutput model. The input phase should generate complete and valid data, the throughput phase should result in identification of relevant causes and statistical patterns, and the output phase should lead to corrective actions that can be implemented in a cost-efficient manner.
For our purpose, the general phases described by van der Schaaf (1991) and Kjellén (1998) will serve as a guide when we compare accident and near miss reporting in two industries: the German nuclear industry (GNI) and the Norwegian offshore industry (NOI). The objective of the study is twofold. First, it seems reasonable to assume that a comparative study of the way accident and near miss reporting is organised will reflect fundamental differences between the two industries. The two ANMASs have different histories, are developed in different national and corporate cultures, and have somewhat different main functions.

Second, although there exist fundamental differences between the two industries, a comparison of the way event reporting and analysis is organised may still offer a potential for learning. By pointing at alternative ways of organising the event analysis, it is imaginable that useful lessons can be learnt about shortcomings and strong points in the two systems. Thus, a comparative study of ANMASs will ideally result in insights that are relevant both with regard to stable and important "background variables", and to features of the ANMASs that are more easily modified and improved.

The present paper is based on two independent studies of ANMASs in GNI and NOI. In both studies interviews with operative personnel, safety delegates, safety officers and managers, and plant/installation managers were conducted. In addition, legal requirements, technical procedures and in-house regulations were reviewed.

\section{THE INDUSTRIES - A BRIEF OVERVIEW}

The GNI, with 20 power plants on 15 sites, was responsible for 30\% of Germany's energy production in 1998. 
The NOI has an even more significant impact of the national economy; in 1997, the industry was responsible for $38 \%$ of the Norwegian export. The Norwegian offshore industry comprises about 100 fixed and movable installations. Deregulation of markets, privatisation, and increased environmental taxes during the last years have reduced the profit margins in both industries. Still, it is not possible to detect a reduced emphasis on safety in official statistics. In GNI, the number of events with varying risk potential have not increased (BfS, 1999), and in the NOI, the number of registered personal injuries, after a strong decrease since the industry's conception in the early $1970^{\prime}$ s, have been quite stable for the last few years (NPD, 1999).

Both the nuclear industry and the offshore industry are high-risk enterprises in the sense that they exhibit complex interactions and tight couplings (Perrow, 1984). Furthermore, both industries have to control tremendous amounts of energy, and the potential for events with catastrophic proportions is thus a factor that both enterprises have to consider.

Even though similar safety challenges exist within the two industries, GNI may be said to have a stronger focus on the technical subsystem (i.e. control of the nuclear chain reaction). On the other hand, NOI has a higher complexity within the social subsystem due to a low degree of standardisation of equipment, and a vast number of suppliers and sub-contractors. Furthermore, the probability of occupational accidents is comparatively high in the offshore industry due to ship and helicopter transports, work in rough weather, and sub-sea operations.

\section{Legal requirements}

In GNI, the procedures related to incident reporting shall be documented in the licensee's operation manuals. The registration of incidents is based on well-defined technical criteria (e.g. KTA, 1985), Every safety relevant component of a nuclear power plant is identified in relevant regulations (BMU, 1992). In the case of a malfunction the incident, its causes and preventive measures should be reported to the authorities. The focus on safety critical components is in part due to the federal structure of Germany. This structure, with a high degree of local autonomy, necessitates safety parameters that are easy to communicate and compare across regional adaptations of national safety legislation.

In NOI, it is mandatory to report fatal accidents, serious personal injuries, personal injuries requiring professional treatment, lost time accidents and other incidents of relevance to safety to. In addition, an oil company has an obligation to keep a record of all incidents registered on the installations operated by the company, and what corrective actions have been taken to prevent recurrences (NPD, 1985).

\section{INPUT - COLLECTION OF INCIDENT DATA}

Whereas each NOI installation typically reports about 900 incidents every year, in GNI only 10-40 incidents are reported from each plant. In addition to different legal requirements, the number of reported incidents is a result of different incident definitions. In NOI incidents are understood as an undesired event that could or does result in loss, i.e. harm to people, damage to property, loss of process and/or environmental damage (DnV, 1998). GNI focus on the availability of predefined safety systems or radiation exposure above certain limits, which means that an incident is defined by criteria given by the authorities (BMU, 1992). In this regime an incident occurs if the safety systems have not withstood an evolving incident. Both definitions are related to the outcome of an incident, but the NOI definition includes potentially harmful events and events that are related to occupational safety on a broader basis than GNI.

In both industries it was possible to identify three groups of potential incident reporters: managers, safety experts (e.g. safety officers and safety delegates), and operative personnel. In GNI the detection of incidents is frequently based on inspections or system warnings. In NOI, on the other hand, operative personnel detect and register most incidents during normal work operations. Again, the difference in reporting practices is partly due to different incident definitions. In addition, offshore work operations are frequently exposing operative personnel to occupational risks. This generates a high number of reports on comparatively minor incidents from operative personnel.

Quality assurance of the registered information was considered critical in both GNI and NOI. Typically, an incident was discussed at team meetings, and the information was evaluated by a number of persons (e.g. managers and safety officers) before the report was officially acknowledged. In NOI only a small portion (about one percent) was formally investigated. In GNI, the majority of reported incidents instigated an investigation. However, due to the high number of reported incidents in NOI, the absolute number of formal incident investigations was quite identical for the average offshore installation and nuclear power plant.

\section{THROUGHPUT - PROCESSING OF INCIDENT DATA}

In GNI, the significance of an incident is rated according to its impact on the environment and the defence-in-depthdegradation (IAEA, 1992). In NOI, on the other hand, each incident is given a risk weight according to the incident's estimated loss potential (i.e. what consequences for personnel, environment and/or material assets the event could lead to if it took place under slightly different circumstances). In both industries the real or potential effects of an incident determined how the incident was processed. In general, the more serious incidents were analysed and handled by central parts of the organisation, while less serious incidents were handled at a local level.

In GNI different in-house ANMASs are used. Significant incidents are reported to the BEVOR database, which is administrated by an independent operator. Both the BEVOR operator and the authorities perform statistical analyses of incident data (Kotthoff, 1999, BfS, 1999). Information on specific incidents is distributed to all nuclear power plants. Besides the formal ANMAS there exist stable and important 
informal contacts between managers of different plants. Many of the interviewees in the GNI mentioned the importance of this contact for experience transfer related to specific incidents. International experience transfer is handled IAEA (IAEA, 1989) who administers the IRS database which is structurally similar to the BEVOR database (Sträter, 1997). Every operator has access to the BEVOR and the IRS database and receives periodical safety reports from the databases.

In NOI, it was possible to observe the same distinction between in-house, inter-organisational ANMAs, and databases operated by the authorities. In 1992, major oil companies and offshore contractors launched a joint project for the development of a common ANMAS. The central database is operated by an independent operator and available on the Internet for subscribers (Synergi, 1999). The authorities operate an additional database that is used to generate analyses of relevance to the industry sector as a whole.

Three main methods are in use for the identification of root causes to incidents in GNI: the Assessment of Significant Event Teams (IAEA, 1990), the Human Performance Enhancement System (INPO, 1994) and the VGB method for optimization of men-machine interfaces (VGB, 1994). In NOI the International Safety Rating System (DnV, 1998) has a domineering position, and the causal analyses are typically performed according to the causal model underlying this safety management concept (see Bird \& Germain, 1986).

However, although the specific methods and causal models are different at a superficial level, both industries seem to be strongly influenced by Heinrich' (1931) domino model of incident causation. This model indicates an inherent orderliness concerning the causes of accidents. The causal chain progress from specific and immediate determinants to global and more distant factors. Furthermore, the model points at managerial or organisational factors as a common origin to incidents, and it upholds a distinction between human error and technological failure in the different phases of an incident.

\section{OUTPUT - INCIDENT DATA AND DECISION MAKING}

Both industries use periodical statistics to identify factors that are relevant to the safety performance of an organisation or specific plant/installation. In the GNI the frequency of component failure is emphasised, while the NOI monitors the frequency of occupational accidents and incidents with major safety relevance (e.g. gas leaks). Both GNI and NOI use aggregated data as a basis for development of general corrective actions. However, interviewees in both industries claimed that the time lag between incident recording and the implementation of general corrective actions was too long.

In GNI every reported incident has initiates a scheduled task order, which can be said to represent a specific corrective action. In NOI each incident on the average generates two corrective actions. The corrective actions related to individual incidents are mainly aimed at plant/ installation specific factors, and have limited value as general risk reducing measures.

Interviewees from both industries reported general problems related to safety management based on experiential data. Is an improved safety record a result of corrective actions, or is it attributable to other factors (e.g. automation or a more experienced workforce)? Is historical information important in avoiding future mishaps when environmental, organisational, and technological parameters are constantly changing? How can history help us to avoid a catastrophe that so far has not occurred? In NOI some the interviewees expressed a form of "reporting fatigue". Although they agreed that incident reporting is an important tool in safety management, they questioned the need to report every little deviance. They expressed scepticism to the utility of detailed analyses of "small oil spills on the deck", and argued that the red tape associated with incident reporting in some cases made it an inefficient way to increase safety.

\section{DISCUSSION}

The present study has pointed at differences and similarities in the accident and near miss reporting practices in two industries. Although important details have been left out from the analysis, some general patterns seem to be identifiable.

Both GNI and NOI are high-risk industries with a potential to cause major accidents or catastrophes.

Furthermore, both industries have a strong focus on incident reporting and analysis. A common understanding of the causes to seemed to be identifiable, and both industries submit incident information to in-house databases, databases at an industry sector level, and to databases operated by the authorities. Feedback from the databases to operative parts of the organisation is made in form of statistical analyses of aggregated data and detailed analyses of single incidents.

There are also important differences between the two industries with regard to how incident information is collected, processed and used. In GNI, the focus is on well-defined safety systems and components, while NOI operates with a more extensive understanding of incidents. These differences are related to legislative and conceptual factors, but must also be seen in light of structural characteristics of the two industries. In GNI the standardisation of safety critical components is far more extensive than is the case in NOI. This makes it possible to investigate component reliability in greater detail, which in turn influence the type of data reported into the ANMAS. It is furthermore likely that the many manual work operations performed in NOI have induced an understanding of the incident concept that has a strong focus on occupational accidents. A final structural difference between the two industries is their risk potential for third parties. While a nuclear power plant can be perceived as a direct threat to the civilian population, this is hardly the case for an offshore installation. This factor may have lead GNI to focus on few and serious events of relevance to the environment, while NOI have maintained a focus on the safety for the work force.

Finally, the different reporting practices in GNI and NOI seem to be related to somewhat different safety management policies. In NOI the so-called iceberg theory (Bird and Germain, 1986) is a popular way to conceptualise the relationship between classes of incidents with varying loss 
potential. For instance, the theory states that there exist a fixed relationship between minor personal injuries and fatal accidents. Since there are few incidents with major consequences, experiential safety management should be based on extensive registration of minor accidents and near misses. If these events are prevented, it is conjectured that the probability of major events is reduced as well. In GNI, the iceberg theory does not seem to be in high fashion, a fact that is reflected in the focus on serious incidents in the industry's ANMASs.

Thus, accident and near miss analysis systems are embedded in a context that strongly influence how incidents are reported and analysed, and how corrective actions are developed and implemented. This context consists of social and legislative factors, structural characteristics of different industry sectors, and safety management philosophies. At a general level, this means that it may be difficult to point at universal requirements to ANMASs. Instead of evaluating a particular ANMAS according to an ideal, it may be more fruitful to ask whether an ANMAS works relative to important frame conditions and background variables. This view furthermore implies that comparisons of safety results between e.g. industry sectors should be done with great care.

To say that the success of an ANMAS should be evaluated in a context does not mean that it is impossible for different industry sectors to learn from each other. For instance, it can be argued that NOI has a lot to learn from the way GNI highlights and handles clearly defined incidents with a large loss potential. On the other hand, GNI may draw useful lessons from the way NOI tries to use information on small deviancies to control the total risk associated with offshore oil and gas exploitation. Attempts to establish experience transfer between industry sectors or national boundaries should, however, always start with the question: "It works for them, but will it work for us?"

\section{REFERENCES}

BfS. (1999). Jahresbericht über Meldepflichtige Ereignisse. Salzgitter: Bundesamt für Strahlenschutz.

Bird, F. E. \& Germain, G. L. (1986) Practical loss leadership. Loganville, GA: Institute Publishing.

BMU (1992). Atomrechtliche Sicherheitsbeauftragten- und Meldeverordnung AtSMV) vom 14. Oktober 1992 (BGBl. I S. 1766). Bundesminister für Umwelt, Naturschutz und Reaktorsicherheit.

DnV. (1998). Managing marine accident investigation and analysis course. Hamburg: Det Norske Veritas.

Heinrich, H. W. (1959). Industrial accident prevention: a scientific approach. New York: McGraw-Hill.
IAEA. (1989). Incident Reporting System (Guidelines to Develop the Analysis Capability of IRS Reports Containing a Human Contribution). Vienna: International Atomic Energy Agency.

IAEA. (1990). Asset Guidelines. Reference Material prepared by the International Atomic Energy Agency for Assessment of Safety Significant Events Teams (IAEA-TECDOC-573). Vienna: International Atomic Energy Agency.

IAEA. (1992). INES: The International Nuclear Event Scale - User's Manual (IAEA-INES-92/01). Vienna: International Atomic Energy Agency.

INPO. (1994). Human Performance Enhancement System: Evaluator Training Manual. Atlanta: Institute of Nuclear Power Operations.

Kjellén, U. (1998). Safety information systems. Norwegian University of Science and Technology, Trondheim.

Kotthoff, K. (1999). Erkenntnisse aus 20 Jahren Auswertung gemeldeter Ereignisse. Köln: Gesellschaft für Anlagen und Reaktorsicherheit.

KTA (Kerntechnischer Ausschuss). (1985). Anforderungen an das Betriebshandbuch (KTA 1201). Köln: Carl Heymanns.

Nevis, E. C., DiBella, A. J. \& Gould, J. M. (1995). Understanding organizations as learning systems. Sloan Management Review, 4, $73-85$.

NPD. (1999). Annual Report. Stavanger, Norway: Norwegian Petroleum Directorate.

NPD. (1985). Regulations relating to the licensee's internal control in petroleum activities on the Norwegian continental shelf. Stavanger, Norway: Norwegian Petroleum Directorate.

Perrow, C. (1984). Normal accidents. Living with high risk technologies. New York: Basic Books.

Ringstad, A. J. (2000). Accident and near miss reporting in the Norwegian offshore industry: an organisational analysis of the Synergi project. (doctoral thesis). Norwegian University of Science and Technology, Trondheim.

Sitkin, S. B. (1996). Learning Through Failure: The Strategy of Small Losses. In: M. D. Cohen \& L. S. Sproull (Eds.). Organizational Learning. Thousand Oaks: Sage.

Sträter, O. (1997). Beurteilung der menschlichen Zuverlässigkeit auf der Basis von Betriebserfahrung (Doctoral thesis). Köln: Gesellschaft für Anlagen- und Reaktorsicherheit.

Synergi (1999). [On line] Available: http:/www.synergi.no

van der Schaaf, T. W., Lucas, D. A. \& Hale A. R. (Eds.). Near miss reporting as safety tool. Oxford: Butterworth-Heinemann.

van der Schaaf, T. (1991). A framework for designing near miss management systems. In T. W. van der Schaaf, D. A. Lucas \& A. R. Hale (Eds.), Near miss reporting as safety tool. Oxford: Butterworth-Heinemann.

VGB. (1994). VGB-Konzept zur Optimierung der Mensch-MaschineSchnittstelle (Human-Factors-System) der Deutschen Kernkraftwerksbetreiber. Technische Vereinigung der Grosskraftwerksbetreiber e.V. 